\title{
Isolation protocol for two-dimensional- polyacrylamide gel electrophoresis analysis of Haloferax volcanii proteome
}

\author{
Edward C. Evans, Troy Horn, Mary Ann Wagner, Michel Eschenbrenner, \\ Cesar V. Mujer, and Vito G. DelVecchio \\ The University of Scranton, Scranton, PA, USA \\ BioTechniques 35:478-482 (September 2003)
}

High-resolution two-dimensionalpolyacrylamide gel electroporesis (2DPAGE) is an important step for elucidating the global view of proteins present in a cell or tissue at any given time, including those with posttranslational modifications and rapid turnover rates (1). The isolation of the majority of proteins produced under defined conditions is one of the most important steps in this type of proteomic analysis.

Isolating proteins suitable for 2DPAGE from salt-loving microorganisms represents a significant challenge. Halophilic archaea such as Haloferax volcanii, a member of the Halobacteriacae family, require 2-5 M salt for viability; at lower salt concentrations, their cells become morphologically distorted, and cell lysis occurs. The cytoplasm of halophiles contains high internal concentrations of $\mathrm{K}^{+}$and $\mathrm{Na}^{+}$, which make it iso-osmotic with its environment. Such high levels of salt present in the cytoplasm interfere with isoelectric focusing and subsequent 2D-PAGE. Although Mojica et al. (2) previously reported a 2D-PAGE analysis of $H$. volcanii proteins, their study examined $\left[{ }^{35} \mathrm{~S}\right]$ methionine-labeled, newly synthesized $H$. volcanii proteins. Our goal was to examine unlabeled accumulated proteins from crude extracts so that the gels would be ultimately suitable for matrix-assisted laser desorption ionization-time of flight mass spectroscopy (MALDI-TOF MS) analysis. Using $H$. volcanii DS2 as a model organism, our laboratory developed an efficient protein isolation protocol that generates high-resolution two-dimensional gels for proteomic analysis.

Culture medium was prepared from two stock solutions. Solution 1 contained $2.14 \mathrm{M} \mathrm{NaCl}, 0.25 \mathrm{M} \mathrm{MgCl}_{2}$,
$30 \mathrm{mM} \mathrm{KCl}$, and $15 \mathrm{mM} \mathrm{CaCl}_{2}$ (all chemicals from Sigma, St. Louis, MO, USA). Solution 2 contained $2 \%(\mathrm{w} / \mathrm{v})$ tryptone and $2 \%(\mathrm{w} / \mathrm{v})$ yeast extract (Fisher Scientific, Pittsburgh, PA, USA). Both solutions were adjusted to $\mathrm{pH} 6.8$ and then autoclaved for 30 min at $120^{\circ} \mathrm{C}$. Three volumes of solution 1 were mixed with one volume of solution 2 to a final volume of $1 \mathrm{~L}$. A 1.8-mL glycerol stock of $H$. volcanii DS2 was then added to the medium and incubated with shaking at $37^{\circ} \mathrm{C}$ at 150 $\mathrm{rpm}$. Growth was allowed to occur until the stationary phase was reached, as indicated by an $\mathrm{A}_{420}$ of $1.8-2.3$. The cells were then concentrated by centrifugation at $3540 \times g$ at $4^{\circ} \mathrm{C}$ for $5 \mathrm{~min}$.

From the recorded absorbance of the cultured cells at $420 \mathrm{~nm}$, we calculated the sample equivalent, or volume of cells, required to obtain an absorbance of 1.0 at $420 \mathrm{~nm}$. Ten sample equivalents of cells were taken and added to a 15 -mL Falcon ${ }^{\circledR}$ Polypropylene Tube (Fisher Scientific). Forty microliters of sample buffer I [0.3\% sodium dodecyl sulfate (SDS), $0.2 \mathrm{M}$ dithiothreitol (DTT), $50 \mathrm{mM}$ Tris-HCl, $\mathrm{pH}$ 8.0, and protease inhibitors; Genomic Solutions, Ann Arbor, MI, USA] were added per equivalent, and the mixture was placed on ice for $10 \mathrm{~min}$. Just prior to use, a protease inhibitor tablet was dissolved in sample buffer I, per the manufacturer's instructions (Complete $^{\mathrm{TM}}$ Protease Inhibitor Cocktail; Roche Applied Science, Indianapolis, IN, USA). The samples were placed in a 3500 molecular weight cut-off (MWCO) Slide-A-Lyzer ${ }^{\circledR}$ Dialysis Cassette (Pierce Endogen, Rockford, IL, USA) and dialyzed against $20 \mathrm{mM}$ Tris (2-carboxyethyl) phosphine hydrochloride (TCEP) (Pierce Endogen) in $50 \mathrm{mM}$ Tris- $\mathrm{HCl}, \mathrm{pH} 8.0$, containing $0.3 \%$ SDS. The use of dialysis tubing instead of cassettes yielded incomplete focusing (data not shown), probably due to residual salts in the sample. Dialysis was conducted in three stages of 2, 4, and $17 \mathrm{~h}$, with the buffer changed between each step. These dialysis steps were critical because crude, undialyzed samples consistently caused the immobilized $\mathrm{pH}$ gradient strips (IPG; Amersham Biosciences, Piscataway, NJ, USA) to overheat during isoelectric focusing, which resulted in incomplete focusing (data not shown). One $4-\mu \mathrm{L}$ aliquot per sample equivalent of sample

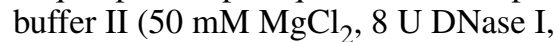
3 U RNase A, 0.5 M Tris-HCl, pH 8.0; Genomic Solutions) was added to the mixture, which was set on ice for an additional $10 \mathrm{~min}$.

Protein concentrations were determined as previously described (3), using the Bio-Rad Protein Assay Stain (Bio-Rad Laboratories, Hercules, CA, USA). Bovine serum albumin (BSA) was used to generate a standard curve. All protein samples and BSA standards were suspended in $20 \mu \mathrm{L}$ of a $10: 1(\mathrm{v} /$ v) mixture of sample buffers I and II.

Proteins were isolated using the protocol of Rafie-Kolpin et al. (4), with slight modifications. All sample preparations were performed on ice with icecold reagents. All centrifugations were for $3 \mathrm{~min}$ at $4^{\circ} \mathrm{C}$ at $10,285 \times g$. Protein extracts $(100 \mu \mathrm{g})$ were mixed with an equal volume of $10 \%$ trichloroacetic acid (TCA), incubated on ice for 5 min, and then centrifuged. The pellet was resuspended in the same volume of 5\% TCA and incubated on ice for $5 \mathrm{~min}$, followed by centrifugation. The pellet was washed twice with an equal volume of acetone, centrifuged, and allowed to air-dry for $10 \mathrm{~min}$. The TCA precipitation and acetone wash sequence described earlier were then repeated, except that a single acetone wash was used. Then, $165 \mu \mathrm{L}$ loading buffer (Genomic Solutions) containing $8 \mathrm{M}$ urea, 4\% 3-(3-cholamidopropyl dimethylammonio)-1-propanesulfonate (CHAPS), $40 \mathrm{mM}$ Tris, $\mathrm{pH}$ 8.0, $65 \mathrm{mM}$ DTT, and $0.01 \%$ bromophenol blue were added and vortex mixed briefly. Lastly, $205 \mu \mathrm{L}$ rehydration buffer (Genomic Solutions) containing $8 \mathrm{M}$ urea, 2\% CHAPS, 10 mM DTT, $2 \%$ carrier 
ampholytes, and $0.01 \%$ bromophenol blue were added, and the mixture was vortex mixed briefly.

IPG strips of linear $\mathrm{pH}$ gradients (3.5-4.5, 4-5, 4.5-5.5, 5-6, 6-11, and 4-7) were rehydrated overnight at $18^{\circ} \mathrm{C}$ with $360 \mu \mathrm{L}$ prepared sample containing $100 \mu \mathrm{g}$ protein. Isoelectric focusing was then performed at $20^{\circ} \mathrm{C}$ for $24 \mathrm{~h}$. A total of $80,000 \mathrm{Vh}$ were delivered to the gels using the Investigator ${ }^{\mathrm{TM}}$ Power Supply (max voltage of $5000 \mathrm{~V}$; max current of $80 \mu \mathrm{A} / \mathrm{gel}$; and end-of-run voltage hold at $125 \mathrm{~V}$; Genomic Solutions) (5).

Each IPG strip was washed for 15 $\min$ in $10 \mathrm{~mL}$ equilibration buffer I (6 M urea, 133 mM DTT, 30\% glycerol, $50 \mathrm{mM}$ Tris-acetate, $\mathrm{pH}$ 7.0; Genomic
Solutions) and then for $15 \mathrm{~min}$ in 10 $\mathrm{mL}$ equilibration buffer II (6 M urea, $2.5 \%$ iodoacetamide, $30 \%$ glycerol, $50 \mathrm{mM}$ Tris-acetate, $\mathrm{pH}$ 7.0; Genomic Solutions). The IPG strips were loaded onto $10 \%$ precast Duracryl ${ }^{\circledR}$ Gels $(\mathrm{Ge}-$ nomic Solutions) $(22 \mathrm{~cm} \times 23 \mathrm{~cm} \times 1$ $\mathrm{mm}$; Tris/tricine/SDS chemistry). Electrophoresis was carried out for $18-19 \mathrm{~h}$ $(500 \mathrm{~V} ; 1600 \mathrm{~mW} / \mathrm{gel})$ at $4^{\circ} \mathrm{C}(6)$.

We fixed and stained the gels in an Investigator Gel Processor (Genomic Solutions). After 2D-PAGE, the gels were fixed for $30 \mathrm{~min}$ in $40 \%$ methanol and $10 \%$ acetic acid and rinsed for 5 min with deionized water to remove excess fixative. The gels were stained with $\mathrm{SYPRO}^{\circledR}$ Ruby (Molecular Probes, Portland, OR, USA) for $12 \mathrm{~h}$ in
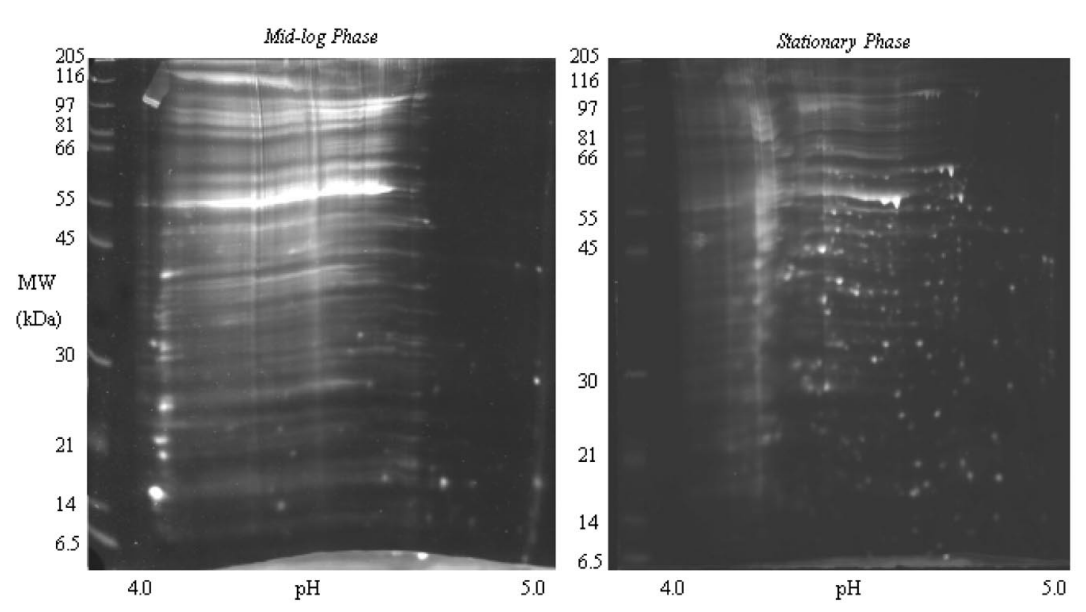

Figure 1. Two-dimensional gels of Haloferax volcanii proteins isolated from mid-log (left panel) and stationary phase (right panel) cultures. MW, molecular weight.
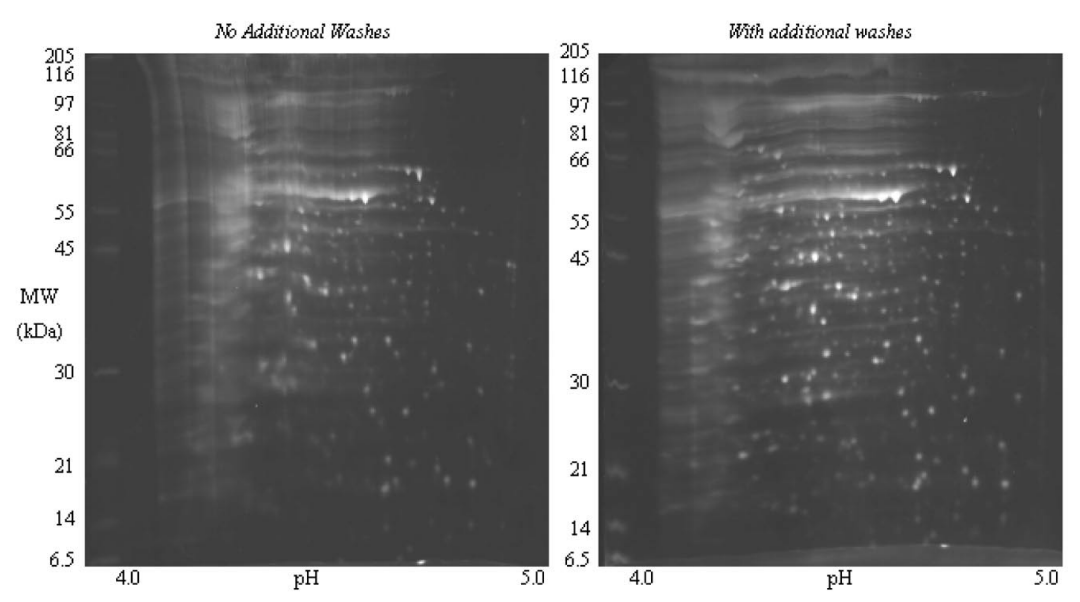

Figure 2. Two-dimensional gels of Haloferax volcanii proteins prepared without (left panel) or with (right panel) two additional trichloroacetic acid (TCA) precipitations and an acetone wash. MW, molecular weight. the dark with gentle rocking. The gels were then submerged in deionized water for $5 \mathrm{~min}$, destained for $30 \mathrm{~min}$ with $10 \%$ methanol and $6 \%$ acetic acid, and stored in $2 \%$ glycerol in the dark. The gels were imaged under $470 \mathrm{~nm}$ light with a LAS-1000 Plus Imager (FUJIFILM Medical Systems, Stamford, CT, USA) (6).

Using this method for the preparation of protein samples, we analyzed two-dimensional gels prepared with overlapping IPG strips from $\mathrm{pH} 3.5$ to 11.0. In total, we detected approximately 600 proteins. However, the majority of proteins are toward the acidic region, pI (isoelectric point) 3.5-5.0.

We observed that there were significant qualitative and quantitative spot differences between samples isolated during the mid-log phase as opposed to the stationary phase. Using IPG strips of $\mathrm{pH} 4.0-5.0$, we observed a 6.7-fold increase in the number of protein spots between the stationary and mid-log phases. The average number of spots detected during stationary phase was 310 , whereas 47 spots were observed in the mid-log phase (Figure 1). It is possible that during mid-log phase, the growth may still be underdeveloped, while during the stationary phase, the organism is in an active metabolic state. The differential expression of these genes may be growth-phase specific and reflects metabolic differences in response to increasing population density, accumulated metabolic products, and nutrient depletion in the media.

Gel resolution was also affected by the bacterial growth phase. Samples isolated from the mid-log phase displayed a large amount of streaking within the molecular mass range of 66-205 kDa. This observation was made using IPG strips of varying $\mathrm{pH}$ ranges. Although some streaking was still evident in the samples isolated from the stationary phase, the resolution was dramatically improved. This allowed for more accurate spot detection and a more precise evaluation of the spot volume (Figure 1).

Washing conditions also proved critical to high-quality results. Impurities in the samples led to bow-shaped protein spots in the gel. Repeating the TCA precipitation-acetone wash sequence considerably reduced the 
streaking and slightly increased the number of visible spots (Figure 2). This observation is consistent with another report that suggests that additional precipitations/washes reduce sample impurities, allowing for subsequent isoelectric focusing to achieve greater separation of proteins in the first dimension, with an increased overall resolution of proteins on two-dimensional gels (7). Additional TCA precipitations limited streaking between 81-97 kDa but were accompanied by spots of less intensity. Washing of samples using ammonium bicarbonate and acetone were also tested. Although these additional washing steps considerably reduced streaking, the total number of protein spots significantly decreased. Therefore, these steps were not incorporated into our final protocol.

In conclusion, we have developed an improved protein isolation protocol for $H$. volcanii that can be used successfully for 2D-PAGE. One major advantage of this method is that it is compatible with the global identification of proteins using MALDI-TOF MS because proteins are not labeled. Significantly more protein spots were noted at the stationary phase versus the mid-log phase. Additional TCA washes during sample preparation improved the spot resolution and decreased streaking on the gels, which, in turn, resulted in enhanced spot detection. The future analysis of the $H$. volcanii proteome may yield valuable information about the organism's ability to tolerate and survive extremely high salt conditions. In addition, this procedure may prove useful for the proteomic analyses of other halophiles.

\section{ACKNOWLEDGMENTS}

This work was supported by grant no. DE-FG02-98ER62592 from the US Department of Energy to V.G.D.

\section{REFERENCES}

1.Fichmann, J. and R. Westermeier. 1999. 2D protein gel electrophoresis, p. 1-7. In A.J. Link (Ed.), 2-D Proteome Analysis Protocols: An Overview, Methods in Molecular Biology, vol. 112. Humana Press, Totowa, NJ.

2.Mojica F.J.M., E. Cisneros, C. Ferrer, F. Rodriguez-Valera, and G. Juez. 1997.
Osmotically induced response in representatives of halophilic prokaryotes: the bacterium Halomonas elongata and the archaeon Haloferax volcanii. Am. Sci. Microbiol. 179: 5471-5481.

3.Bradford, M.M. 1976. A rapid and sensitive method for quantitation of microgram quantities of protein utilizing the principle of protein-dye binding. Anal. Biochem. 72: 248-254.

4.Rafie-Kolpin, M., R.C. Essenburg, and J.H. Wyckoff. 1996. Identification and comparison of macrophage-induced proteins and proteins induced under various stress conditions in Brucella abortus. Infect. Immun. 64: 5274-5283.

5.Wagner, M.A., M. Eschenbrenner, T.A. Horn, J.A. Kraycer, C.V. Mujer, S. Hagius, P. Elzer, and V.G. DelVecchio. 2002. Global analysis of the Brucella melitensis proteome: identification of proteins expressed in laboratory grown culture. Proteomics 2:1047-1060.

6.Eschenbrenner, M., M.A. Wagner, T.A.
Horn, J.A. Kraycer, C.V. Mujer, S. Hagius, P. Elzer, and V.G. DelVecchio. 2002. Comparative proteome analysis of Brucella melitensis vaccine strain Rev 1 and virulent strain, 16M. J. Bacteriol. 184:4962-4970.

7.Janson, J.C. and L. Ryden. 1998. Isoelectric focusing, p. 495-528. In J.-C. Janson and L. Ryden (Eds.), Protein Purification: Principles, High Resolution Methods, and Applications. John Wiley and Sons, New York.

Received 17 April 2003; accepted 12 June 2003.

Address correspondence to Vito G. DelVecchio, Institute of Molecular Biology and Medicine, The University of Scranton, 800 Linden Street, Scranton, PA 18510, USA. e-mail:vimbm@aol.com

\section{Rapid selection of Drosophila S2 cells with the puromycin resistance gene}

Takayuki Iwaki, Mariana Figuera, Victoria A. Ploplis, and Francis J. Castellino University of Notre Dame, Notre Dame, IN, USA

BioTechniques 35:482-486 (September 2003)

The Drosophila melanogaster Schneider 2 (S2) cell line was established in 1972 (1). These cells grow rapidly in culture at room temperature without a need for $\mathrm{CO}_{2}$. Various expression vectors have been constructed that facilitate both constitutive (2) and inducible expression (3). Many studies have indicated that the generation of recombinant proteins with $\mathrm{S} 2$ cells is more desirable than other methods, since native proteins derived from S2 cells do not usually interact with those derived from mammalian cells. Despite these advantages, only two markers (i.e., hygromycin and blastcidin) are commercially available for establishing stable transformants (Invitrogen, Carlsbad, CA, USA). Additionally, approximately 2 weeks are required to establish a stable transformant with blastcidin, and more than 3 weeks are needed with hygromycin.

Figure 1 illustrates the structure of a co-expression vector for $\mathrm{S} 2$ cells, $\mathrm{pCo}-$ PURO, which contains the Copia pro- moter, puromycin $\mathrm{N}$-acetyl-transferase (pac), and the simian virus 40 (SV40) poly(A) sequence. The cDNA coding for the pac sequence was digested from the puromycin resistance module (Stratagene, La Jolla, CA, USA) with restriction enzymes HindIII and $\mathrm{XbaI}$ (both from Promega, Madison, WI, USA). This pac sequence was blunted with T4 polymerase (Promega) and ligated with T4 ligase (Promega) to the EcoRV site of pBSIISK+ (Stratagene). After determination of the correct orientation of the insert with several restriction digestions, the pac sequence in pBSIISK + was digested with BamHI and $\mathrm{XhoI}$ (both from Promega) (Figure 1, Fragment 2). The plasmid, pCoHYGRO, which contains the Copia promoter, the hygromycin resistance gene, and the SV40 poly(A) sequence (Invitrogen) was digested with $\mathrm{XbaI}$ and $\mathrm{XhoI}$ to remove the Copia promoter and the hygromycin resistance gene (Figure 1, Backbone 1).

The sequence of the Copia promoter 